\title{
Bargaining on your Spouse: Coasean and non-Coasean Behaviour within Marriage.
}

\author{
John Douglas Skåtun \\ University of Aberdeen \\ 15 th August 2016
}

\begin{abstract}
Legal structures of divorce settlements are important in how marital division of labour impacts on divorce. They affect not only divorce welfare but also within-marriage allocations. A central question in this context is whether or not intra-marital bargaining is Coasean, where Coasean bargains are characterised by the costless transfer of utility between spouses when property rights are well defined. In Coasean bargains divorces are efficient in the sense that they cannot occur when the joint surplus within marriage is larger than the sum of individual divorcees' values outside marriage. This is because the spouse with the highest value can always compensate the spouse who wants to leave, and thus persuade her/him to stay. Under nonCoasean bargaining inefficient divorces can occur, due to the absence of costless side-payments. This paper offers a theoretical framework to identify Coasean and non-Coasean behaviour. Whilst an increase in the spouse's wage always reduces (increases) non-Coasean labour supply (home production), it increases both labour supply and home production under Coasean bargains. Observing labour supply falls after a divorce will again indicate Coasean bargaining. The paper provides a possible explanation for why both males' preferences for stereotypical work division and females' preference for non-monetary work aspects persist.
\end{abstract}

Keywords: Marriage, Divorce, Coasean Bargains, non-Coasean behaviour.

IEL classifications: J12, J22, K3 
In the seminal work by the 1991 Nobel laureate of economics; Ronald Coase (1960), it was argued that property rights could solve the problems of externalities. For if bargaining was frictionless and property rights were well defined, thereby characterising Coasean bargains, then efficient outcomes would automatically follow. In the context of marriages, divorces are efficient and should only occur if the combined utility after a break-up is larger than the combined utility within the marriage. Consider therefore a situation where one spouse wants to leave the marriage and the other wants to stay, but where at the same time their joint combined surplus is greater within than outside marriage, thereby classifying this marriage as efficient (for this is in this instance the situation that generates the highest aggregate surplus) and the potential divorce as inefficient. Under such a circumstance Coasean bargaining allows the spouse with the highest value of the marriage to transfer utility without cost to the partner who wishes to leave. Since the net value of one spouse exceeds the net disutility of the other, the Coasean bargain will transfer funds from where the value is greater to where the value is negative, rendering both spouses better of post bargaining in the marriage than in a potential divorce. In other words if one spouse wishes to leave from such a jointly high-value marriage there is always a Coasean side payment to be made, consisting of either physical material goods/wealth or more ephemeral goods, such as the effort exerted by a spouse in the marriage through more marriage production, such as home production or simply through higher levels of love and attention, thereby rendering both spouses better off in marriage. Note that inefficient marriages will break down even in the Coasean case when the joint value or surplus is negative. However, in the absence of Coasean bargains, inefficient breakdowns occur, that is where divorces proceed despite the sum of utility of the two married partners is higher within than outside the marriage. Non-Coasean behaviour ensues when the condition of free flow of transfers is violated, in which case it will often, but not always, lead to inefficient breakdowns of marriage. It is the theoretical analysis of the contrast between these two separate types of behaviour which forms the basis of this paper. The theoretical predictions that follow are not empirically investigated here, but are instead left for future work.

Thus, in the economics of marriage and divorce, a simple question has been asked: Do married couples engage in Coasean bargains that ensure efficiency, or are marriages characterised by non-Coasean behaviour where inefficient divorces may ensue? This matter has stemmed from the substantial empirical body of work that has investigated the effects of the change in divorce laws on divorce rates. The literature 
emerged from the seminal discussion (Becker 1973, 1974; Becker et al. 1977) who argued the move to unilateral divorces should have no impact on divorce rates as long as there was Coasean bargaining in the marriage. However, it was a line of research that did not result in a strict consensus, for whereas some papers argued the trend in divorce rates remained unchanged others took the contrary stand.

This paper will not directly seek to join either side of the divide over the impact of the introduction of unilateral divorce laws, but will instead contribute by opening a new front. An agnostic approach is adopted by investigating the Coasean and the nonCoasean cases in turn. Thus rather than presupposing either of the two regimes both cases will be investigated so as to compare and contrast the case specific labour market and home production outcomes. As such new insight is gained providing more light on the issue, illuminating some existing empirical findings.

Whilst there are some similarities across the regimes there are also notable differences. So though in both cases divorce rates fall with increases in marital production abilities other effects are more dissimilar. Coasean married employment exceeds the non-Coasean equivalent employment. Under Coasean behaviour an increase in the spouse's wage encourages own labour supply and that it is sometimes possible for employment to be higher in marriage than divorce. Contrast this to our non-Coasean finding where increases in the spouse wage reduces own labour supply, and where nonCoasean divorced employment unambiguously exceeds married employment.

Legal frameworks, with their rules that characterise property rights within and out of marriage, play an important role in the time allocated to labour market and marital production activities. This is a largely under-exploited avenue of research. Thus this paper will also seek to add to our understanding of how the courts' division of marital income and assets in the event of a divorce interacts with a marital couple's behaviour within marriage and the potential decision to seek a divorce. The model will demonstrate how different sharing regimes produce different effects. With an increasing trend towards more equitable sharing of income in the event of a divorce special attention is afforded this regime, without explicitly restricting other sharing arrangements.

\section{Related Literature.}

The literature that investigated the effect of changes in divorce law can, as mentioned above, be subdivided into those papers that supported Coasean behaviour and those who did not. Though parts of the literature (e.g., Peters 1986, 1992) argued that the introduction of unilateral divorce laws in the US had no effect on the overall 
divorce rate, other relevant papers (e.g., Allen 1992; Friedberg 1998) claimed the opposite. Some offered the view that the effect was only transitory (Wolfers 2006). A European cross country study (González and Viitanen 2009) reported significant effects of changes in divorce laws on divorce rates.

One strand in the non-Coasean tradition did not explicitly model the frictions. Some papers (Rasul 2006) simply assumed the absence of Coasean bargains, arguing that the change to unilateral divorce laws could cause those married to be better matched than those previously married under mutual consent divorce laws, whereas others (Matouschek and Rasul 2008) argued marriage contracts were most typically drawn up for commitment reasons. A strand of literature explicitly modelled the process (Peters 1986) and argued the frictionless assumptions of Coasean bargaining were violated when the individual shocks were privately observed. The literature also provided a contracting reason (Rainer 2007) as well as the argument the violation of Coase could happen through the generation of transaction costs arising from hold-up associated with human capital investment (Geddes and Lueck 2002).

Another strand of ensuing literature from the seminal work of Becker (Becker 1973, 1974), whose focus included the division of labour and human capital acquisition and where gender differences emerged for comparative advantage reasons, examined the incentives to partake in investment within the marriage. This strand can for our purposes broadly be subdivided into two. On the one hand are some papers who did not consider divorce at all (Lundberg and Pollack 1993), by presenting a convincing argument that the valid threat point in the marital bargain was not contained in divorce, but instead found in the non-cooperative outcome within the marriage. Thus the outside option of divorce was of little interest in their model. On the other hand are papers where divorces arose from a sufficiently severe common unavoidable exogenous shock to the marriage, but where it was critically assumed that no action was undertaken to soften the blow. This therefore implied divorce rates were characterised solely by the size of the exogenous shock. Such exogeneity issues arose for instance in Rainer (2007), who investigated the incentives of prenuptial agreements and included a discussion of how the outcome was affected by different levels of divorce, but not how the choices made affected divorce rates. Another example is Lommerud (1989) who discussed how the risk of divorce could affect the division of labour within the marriage, but not vice versa. The model presented below will not investigate investments and differs further from this literature in another important respect: The Coasean part of our model will also investigate the individuals' evading actions that may affect divorce rates. Thus the 
focus in the Coasean analysis is wider than the previous literature mentioned above where divorce rates are purely exogenous.

In addition, the following model's comparative analysis of Coasean and nonCoasean behaviour distinguishes itself from the existing literature in at least two further respects. First it differs in its treatment of private and public goods. Most of the literature assumed that some goods were private, usually those derived in the labour market, whereas others were assumed to be public, usually those derived in home/marriage production, see discussion by Bergstrom (1977). The present paper adopts instead the assumption (Peters and Siow 2002) that goods whether produced at home or in the market should be public, though our paper in contrast also assumes that leisure is private. Second, the model presented below is unique and novel in its division of time. We know of no other paper on marriage and divorce that has split time between market work, marriage work and leisure. In contrast to that approach, the literature invariably assumed time spent in home/marriage production and leisure was one and the same. Not only has this been a gross simplification, it has also been a feature that could force a perfectly negative correlated co-movement between market work and home production. For, if time could only be spent by supplying labour to market or home production, it should follow that time in marriage production inevitably would have to fall in response to a rise in the time spent in the labour market. Thus the tripartition of time introduced in this paper is more than a trivial extension of the model, as it provides the means to which a positive correlation between production in the home and market sector is not automatically excluded. It is therefore quite possible not always to arrive at the conclusion, common in the comparative advantage literature, that marital survival is helped by a division of labour that specifies specialisation. Nor is a more equal division of labour where females have a high degree of financial independence necessarily detrimental to marital success. Without yielding definite answers, the paper sheds further light on the question of whether it is better for spouses to separate their tasks, so that one stays at home and the other works in the labour marked, or whether the couple could improve their prospects by sharing the responsibility of home and market production more equally.

Furthermore, this paper is also linked to other research (Browning and Chiappori 1998; Chiappori et al. 2002), who developed a collective framework for intrahousehold bilateral decision processes, that encompassed a range of collective bargaining and contracting models. Whereas the non-Coasean part of the model is less cooperative than that literature, the analysis offered in this paper can be viewed as more cooperative than the non-cooperative models (Chen and Wolley 2001; Konrad and 
Lommerud 2000; Lundberg and Pollak 1993, 1994; Manser and Brown 1981; McElroy and Horney 1981; Vagstad 2001), where it was typically assumed that some goods were private goods. Instead our paper assumes that all goods (apart from leisure) are public to the extent that they are shared equally amongst the spouses.

The paper sits within a wider literature that investigated the determinants and causes of divorce as well as its effects on outcomes, for an overview see Amato (2010). The model presented below is thus capable of shedding light on some of the many causes mentioned in the literature which range from issues such as changes in attitudes and perceptions (Thornton and Young-DeMarco 2001), increases in female labour supply (Özcan and Breen 2012) and changes in female earnings (Tamborini et al. 2015).

\section{Division of Income and Legal Rules.}

Since property rights within marriage and divorce depend on the legal framework a brief discussion of some judicial traditions and recent prevailing trends is included in this section. For an economic model which has linked divorce and legal structure, see Clark (1999).

If $\mathrm{s}^{\mathrm{i}}\left(\mathrm{s}^{-\mathrm{i}}\right)$ denotes the share of aggregate wealth an individual (her/his spouse) receives after a divorce, then an equitable division rule would imply; $\mathrm{s}^{\mathrm{i}}=\mathrm{s}^{-\mathrm{i}}=1 / 2$. Whilst this may seem restrictive, it is in many instances close to reality. Indeed in many judicial districts this legal practice is well established. Such legal jurisdictions include those that are governed by Community of Acquests Laws present in the US community property states, that include Arizona, California, Idaho, New Mexico, Louisiana, Washington, Nevada, Texas, Wisconsin, and Alaska, where property acquired by either spouse while married automatically becomes joint property, and European legislative authorities such as Scotland (distinct from England and Wales) (see Smith 2003), where property accumulation during marriage is divided equally. Furthermore, it is equally germane in countries with Universal Community Laws such as the Scandinavian countries where all property is assumed to be available for equal division. All other US states other than the Community of Acquest States (apart from Mississippi) are Equitable Distribution States and could at a push said to be close to the assumption of $s=1 / 2$ in that division in these states should at the least be fair, if not necessarily equal. One can in addition argue, with the support of arguments proposed by Smith (2007), that limiting the study to this rule, $\mathrm{S}^{\mathrm{i}}=\mathrm{S}^{\mathrm{i}}=1 / 2$, is becoming less restrictive with time as such an application of family law is becoming increasingly widespread with changing social norms. 
Common law countries with Judicial Discretion, such as England, for instance, who traditionally awarded financial assistance fairly on account of future needs of spouses have seen recent moves toward equality in the division of marital surplus, see the House of Lords Judgment (2000). This ruling, which concerned the case White v. White, made legal precedence for divorcing couples, deeming the contributions of the breadwinner and home maker equally valid and effectively deciding that equal sharing should become the default position. It stated: "As a general guide, equality should be departed from only if, and to the extent that, there is good reason for doing so" (p.1). However, it should be noted that legal matters in England surrounding the principle of equal sharing are considerably more complicated than a blanket equal sharing of marital assets and income. Indeed it is possible for the courts to award, on the grounds of several factors, the lower earning party in a divorce settlement less and also more than their equal share of property. These factors include wealth and age at the time of marriage, the accumulation during marriage, the length of marriage and needs based considerations. Nevertheless the principle of equal sharing following White v. White prevails as the predominant principle. The ruling was followed by a series of high profile cases in England, suggesting the preceding court ruling had a marked effect, as exemplified in the House of Lords Ruling (2006) concerning two divorces. First in Miller v. Miller, where Alan, former husband of Melissa, unsuccessfully appealed against a $£ 5 \mathrm{~m}$ divorce settlement. And second in Mcfarlane v. Mcfarlane, where Julia, was awarded $£ 250,000$ a year and half of her ex-husband's $£ 3 m$ estate.

All these cases and several more indicate a move to more equitable sharing rules within divorce. How many more couples may practice equal sharing irrespective of legal structure is likely to be a reflection of social norms and is ultimately a matter for empirical verification. Though the model is not solely restricted to the case of equitable sharing, it should be noted that the equity of partners within and out of marriage seems ever more realistic and that such sharing arrangements will therefore in the following be afforded special attention.

It is, despite the previous paragraphs, important to note that it may not be the share of wealth the parties receive within wedlock and in divorce that by itself is important, but rather how the share changes should the parties make the transition from marriage to divorce. In other words, our model, that has chosen a benchmark of equal sharing within a marriage, could without loss of generality be extended to situations where the married spouses are attributed different shares when married. The driver of the results in that augmented model would then be whether or not the spouses receive the same share when divorced. It can therefore be argued that the special case in 
the model below of an equitable divorce division, $\mathrm{s}^{\mathrm{i}}=\mathrm{S}^{-\mathrm{i}}=1 / 2$, can effortlessly be extended to situations and legal regimes where the couple are given the same proportion of funds in divorce as in marriage, as seems to be the basis of more "traditional" needs based divisions, such as in equitable distribution states.

\section{The Theoretical Model.}

A one period model of marriage is presented where two married individuals $i$ and -i consider the pros and cons of staying in wedlock. It is critically assumed that marriages have previously been entered into voluntarily so that the ex ante expected value of marriage, $E V_{m}^{i}$, exceeds the value of a divorce $V_{d}^{i}$. However at the beginning of the period each individual receives marriage specific information, through the experience of a marriage specific independently distributed random idiosyncratic shock $\varphi^{i}$ with an expected value of zero and an upper and a lower bound of $\varphi^{H}$ and $\varphi^{L}$. Individual i's ex post value of marriage, $V_{m}^{i}$, is therefore $V_{m}^{i}=E V_{m}^{i}+\varphi^{i}$ and no longer guaranteed to exceed the value of a divorce. Thus when the shock has been revealed the individuals either separately or together consider whether they should continue the marriage or go down the divorce route. If the shocks are favourable the marriage survives, whereas if the shocks are bad enough they will result in a split, immediately triggering a divorce. The individual shock, whether good or bad, has a lasting effect on the individual if the couple remains married but there is otherwise no scarring out of wedlock so the shock is not felt if divorced.

Individuals optimise either separately (non-Coasean) or jointly (Coasean) to maximise the value of marriage, whereas they individually maximise their individual values of divorce. Thus they trade off the (maximum) value of the marriage against the (maximum) value of a divorce. It should be noted that it is assumed that the shocks are exogenously given, and are not in influenced by individual behaviour. However, as has been pointed out in previous studies, shocks could reflect changes in trust and love, incidents of infidelity, unexpected changes in wealth, changes in preferences or health status, incidents of domestic violence, verbal and non-verbal conflict (Clements et al. 2004; DeMaris 2000; Hall and Fincham 2006; Lawrence and Bradbury 2001; Ogolsky et al. 2015; Previti and Amato 2004), some of which have been reflections of individual behaviour and choices not modelled here. Instead we concentrate on the analysis of the division of time within the marriage.

Whilst individuals may divide their time between varieties of activities such as market work, house/yard work, child care, services/shopping, personal care, education, 
organizations, social entertainment, active leisure, and passive leisure, as found in Rupert et al. (2000), aggregate measures of market work, home production and leisure are preferred for the purpose of modelling simplicity. It is noted however that whilst home production may involve the production of physical goods and services it may also involve time spent investing in the relationship. It is also noted that the many reasons that have been given for how and why home production have been split (Davis and Wills 2015), are not investigated here and are therefore beyond the analysis of this paper. In the present model a married individual divides her/his time between 1) time $l_{m}^{i}$ spent in the labour market, 2) marital time $m^{i}$ that might either be spent on physical marriage specific goods and services production or on intangibles such as attention and love ${ }^{1}$ and 3) leisure time $r_{m}^{i}$, which is the only pure private good in this model. This is a totally selfish activity, and considerations of whether the individual's time is spent with her/his spouse are not entertained. Whilst this is a simplistic assumption and does not take into account positive feedback spouses may have from spending leisure time together, as discussed by Dew and Wilcox (2011), any gift exchange is to the defence of the model covered by the choices of time spent in home and market production. Total time is normalised to unity so that; $l_{m}^{i}+m^{i}+r_{m}^{i}=1$. An additional hour spent in labour returns the wage rate, $w^{i}$, implying a take-home pay of: $w^{i} l_{m}^{i}$. The value of an additional hour of marriage specific production is reflected by the parameter $A^{i}$, which is a technological production factor that enhances marital production $A^{i} m^{i}$. Though it should be noted that $A^{i}$ and $w^{i}$ are exogenous to the model and taken to reflect innate ability in performing the respective tasks, they may nevertheless be affected by pre-marriage investments; that is past human capital investments in both markets, accumulated through 1) the educational system, 2) past labour market experience and 3) past household/relationship activities.

Goods, whether produced in the market or at home, are common, public and divided equally amongst the spouses. This assumption may be stronger than needed. In a more general Nash model of bargaining over income, income is split according to bargaining strength. However if we assume that all individuals are symmetric and have equal bargaining strength it would imply that any cake divided should be divided

1 This is in the spirit of Parkman (2004), who discussed marital gifts that benefit a spouse. Such gifts may be physical in nature, manifested for instance through physical presents but also of a more psychological kind and include attention given, empathy, affection and communication in time spent together. Parkman showed that such gift exchanges were important factors that ensured a successful marriage and that divorcees reported lower levels of such gift exchanges in their failed marriages than did those who continued to be married. 
equally, which is consistent with our assumption that all income and production is split equally between the sexes. Thus the individual specific monetary values within marriage derived from the labour market and marital specific production are given by $\frac{w^{i} l_{m}^{i}+w^{-i} l_{m}^{-i}}{2}$ and $\frac{A^{i} m^{i}+A^{-i} m^{-i}}{2}$ respectively. The spouses possess strictly concave utility functions, separable across market production, marital specific production and leisure, where the utility derived from market goods is $u($.$) , the utility from marital$ specific production goods is $v($.$) and the utility from leisure is v($.$) . To reflect the$ disutility of work and marital production, the spouses each face costs associated with the two productive activities which are solely a function of their own time spent in that activity. Strict convexity of the cost functions $c_{l}^{i}\left(l_{m}^{i}\right)$ and $c_{m}^{i}\left(m^{i}\right)$ is imposed, for market and marriage specific production respectively.

Females and males share the same utility functions and are identical in all other respects. Whilst this is a strong assumption it does maintain a simplicity that generates clarity of results. On the other hand preferences and behaviour of females and males may differ substantially in several respects that are also pertinent to marriage markets. Females have been shown to be more risk averse than males (Agnew et al. 2008; Borghans et al. 2009; Hartog et al. 2002). Females may also differ in respect to trust, though empirical evidence has been mixed (see Croson and Gneezy 2009 for discussion). They also tend to exhibit different social preferences to males: There has been evidence (Alesina et al. 2011) from different surveys in a variety of countries that females have been more likely than males to be pro-redistribution. Child bearing and child care is also likely to impact differently on the sexes. Females have a shorter period of being reproductive than males, which has caused differences in labour and marriage market behaviour (Siow 1998). Since this paper concentrates on Coasean bargains it is worth noting that females have also been shown to be more likely to be better negotiators when bargaining on behalf of others (Bowles et al. 2005) such as their own children. Bargaining strength of females is therefore likely to be dependent on context and in as much as bargaining strength is reflected in time preferences it may reveal an underlying mechanism that determines changes in relative bargaining strengths between couples. Finally it is worth mentioning that behaviour within marriage could be determined by gender identity (Akerlof et al. 2000). This paper provides a model that assumes no difference between genders in preferences, but that nevertheless reflects key aspects of relational behaviour within marriage.

It follows that the net value, $V_{m}^{i}$ within the marriage can be characterised by: 
$V_{m}^{i}=u\left(\frac{w^{i} l_{m}^{i}+w^{-i} l_{m}^{-i}}{2}\right)+v\left(\frac{A^{i} m^{i}+A^{-i} m^{-i}}{2}\right)+v\left(1-l_{m}^{i}-m^{i}\right)-c_{l}^{i}\left(l_{m}^{i}\right)-c_{m}^{i}\left(m^{i}\right)+\varphi^{i}$

In order to pin down the survival/divorce probabilities further, one needs to consider each individual's outside divorce opportunity, $V_{d}^{i}$. The analysis of the impact of children, from whom in practice the divorcee of course may derive utility well beyond marriage is excluded from the analysis. Indeed, no marriage specific production takes place after a divorce and the benefits from being productive in marriage are forever zero in the event of a marital breakdown. The same is not the case for labour market production. Marital production stems in other words from (marriage) specific human capital, whereas an individual's labour market income is derived from general (between marital states) human capital, which is perfectly transferable from marriage to divorce.

In the event of a divorce, a court sets the exogenously determined share, $\mathrm{s}^{\mathrm{i}}$ of the aggregate labour income a single individual receives, whilst the spouse's share is $\mathrm{s}^{-\mathrm{i}}=1-\mathrm{s}^{\mathrm{i}}$. With labour market income depending on how much is worked, it is assume the courts can deduce the expected marital labour supply of both parties and therefore the expected income generated had the relationship lasted. In this way all assets and income streams can be valued and verified perfectly. Though this is a simplification, it can nevertheless be noted that divorce proceedings are often associated with significant court resources spent on the verification of the size of the assets held by the respective parties in a divorce.

The model allows the divorcees' work to vary across marital states, as found in the literature (Gray 1998; Johnson and Skinner 1986; Tamborini et al. 2012), so that individual i's married and divorced labour supply are not necessarily the same. Note also, though the divorced individuals lose the consumption of the marriage specific good, they will in exchange gain some outside additional value $H^{i}$ of being single. One could suspect that this would be correlated with the shock $\varphi^{i}$ if this latter variable is associated with infidelity as argued in previous studies (Hall and Fincham 2006; Previti and Amato 2004). Marriage dissolution is also likely to be affected by frictions in the remarriage market, where costly search, as discussed in Becker et al. (1977), plays an important role ${ }^{2}$. Thus variables such as age could add to marital stability, as found by Weiss and Willis (1997). One may also, on the one hand, expect $H^{i}$ to reflect positive changes in labour fortunes and that the wage one could now obtain is higher, since the

\footnotetext{
${ }^{2}$ How the cost of such search is affected by innovations in internet dating is an interesting subject that is excluded from this analysis. However it should be noted that though dating has become easier, that the dating process is itself a costly process, so that search cost though lower may at least for some not be insignificant.
} 
dissolving household has made labour mobility easier so that labour market search could be facilitated (Mortensen 1988). However one may, on the other, hand also expect $H^{i}$ to reflect the negative income effects such as those females face after a divorce as for example was found in van Damme et al. (2009) and for males; the loss of the male marriage wage premium (see e.g., Hersch and Stratton 2000). Whilst it is recognised that all these issues are important, they will in the remaining not be considered as the emphasis remains rooted in the analysis of Coasean versus non-Coasean behaviour.

Thus the value, $V_{d}^{i}$, of the outside opportunity is given by:

$V_{d}^{i}=u\left(s^{i}\left(w^{i} l_{m}^{i}+w^{-i} l_{m}^{-i}\right)+w^{i}\left(l_{d}^{i}-l_{m}^{i}\right)\right)+v\left(1-l_{d}^{i}\right)-c_{l}^{i}\left(l_{d}^{i}\right)+H^{i}$

The net value to a divorcee consists therefore of the utility of consumption and leisure less the cost of labour market work and plus the additional value of the outside option. Note labour market income (consumption) is now comprised of two main elements; $s^{i}\left(w^{i} l_{m}^{i}+w^{-i} l_{m}^{-i}\right)+w^{i}\left(l_{d}^{i}-l_{m}^{i}\right)$, the share of joint income allocated to the divorcee and the change in income resulting from a change in labour supply after marriage. The latter part; $w^{i}\left(l_{d}^{i}-l_{m}^{i}\right)$ is equal to zero in the case where labour supply does not depend on marital status, is positive if labour supply increases after divorce and is negative if the opposite is true.

\section{Coasean bargains versus non-Coasean decisions.}

If bargaining is costless the Coase (Coase 1960) theorem applies. Divorces would then be deemed efficient (Becker et al. 1977; Becker 1991) and would never occur as long as the couple's joint surplus is greater within as opposed to outside marriage. Should the joint surplus satisfy such a criterion, side payments can be used to allow them to "work it out". In the context of our model, for the case when $V_{m}^{i}<V_{d}^{i}$, but where $V_{m}^{i}+V_{m}^{-i} \geq V_{d}^{i}+V_{d}^{-i}$ there now exist a transfer, $\mathrm{T}$, from individual -i, to the spouse i such that: $V_{m}^{i}+T \geq V_{d}^{i}$ and $V_{m}^{-i}-T \geq V_{d}^{-i}$, ensuring marital survival, leaving neither worse off and may render one or both better off as compared to a divorce.

Coasean transfers are not modelled as "strict" monetary exchanges, but take instead the form of changes in the time spent in the labour market and marriage specific production. With leisure being a private good, it can be foregone to effectively facilitate a transfer from the individual to the spouse, who may consume more market and/or marital goods. Thus an individual with a discontented spouse could seek to placate the partner with higher exertions in the marriage, either by working more to increase labour income or by increasing efforts at home to enhance marriage specific production. 
In contrast, in the absence of Coasean bargains and transfers $V_{m}^{i}<V_{d}^{i}$ will always invoke a unilaterally initiated divorce. A divorce will in that case occur even when it is not efficient, that is even when $V_{m}^{i}+V_{m}^{-i} \geq V_{d}^{i}+V_{d}^{-i}$.

Consider first the absence of Coasean bargains. Here the individuals will seek a unilateral divorce as long as $V_{m}^{i}<V_{d}^{i}$ implying a person specific critical shock, $\varphi_{*}^{i}$, (such that $V_{m}^{i}=V_{d}^{i}$ where $\varphi_{*}^{i}=V_{d}^{i}-E V_{m}^{i}$ ) for each individual, such that any realisation of a shock smaller than this triggers a divorce. The critical shock is therefore governed by:

$$
\begin{aligned}
\varphi_{*}^{i}= & {\left[u\left(s^{i}\left(w^{i} l_{m}^{i}+w^{-i} l_{m}^{-i}\right)+w^{i}\left(l_{d}^{i}-l_{m}^{i}\right)\right)-u\left(\frac{w^{i} l_{m}^{i}+w^{-i} l_{m}^{-i}}{2}\right)\right]-\left(c_{l}^{i}\left(l_{d}^{i}\right)-c_{l}^{i}\left(l_{m}^{i}\right)\right) } \\
& +H^{i}+v\left(1-l_{d}^{i}\right) \\
& -v\left(1-l_{m}^{i}-m^{i}\right)-\left[v\left(\frac{A^{i} m^{i}+A^{-i} m^{-i}}{2}\right)-c_{m}^{i}\left(m^{i}\right)\right]
\end{aligned}
$$

Further understanding of expression (3) can be gained by considering a specific case. Assume working time is independent of marital status, as occurs when jobs are associated with fixed hours that cannot be altered. Assume in addition an equal postdivorce split of labour income, so that $\mathrm{s}^{\mathrm{i}}=1 / 2$, leading the expression within the bracket of the first line of the right hand side of expression (3) to cancel out. If non-labour derived net benefits within marriage, as represented by the third line exceeds the nonlabour benefits outside marriage, represented by the second line, it follows that the shock will have to be negative for the individual to desire a marital exit. Such an individual will on average want the marriage to survive.

It can be noted that the critical shock will typically differ between the two individuals in a married couple, even with identical utility and cost functions, since the natural abilities, as reflected by $w^{i}$ and $A^{i}$, and the preference, $\mathrm{H}^{\mathrm{i}}$, for the outside option will in general vary between partners. Because in addition the shocks are idiosyncratic, it is therefore quite possible for inefficient divorces to occur.

It follows from (3) that a smaller shock is required to dissolve the marriage with a higher outside option, $\mathrm{H}^{\mathrm{i}}$. There is a degree of abstraction away from two issues in this respect. First, the choice of how to allocate time between work and home may impact on the probability of meeting an alternative mate. This is not consider here, but has been studied elsewhere in the literature (McKinnish 2007) where those who worked with a larger fraction of co-workers of the opposite sex were shown to be more likely to divorce in the future. Second, and yet again beyond this paper is the possibility found in the literature that individuals would seek to improve their outside option when divorce 
became more likely (Johnson and Skinner 1986) so that the anticipation of future divorce could be coupled with greater female labour force participation.

With a similar expression as (3) for the spouse, the overall probability of a divorce/marital survival in the non-Coasean case is represented in Figure 1.

\section{Figure 1 here}

Here the incidence of marital survival is given by the top right rectangular area ${ }^{3}$.

Now consider the Coasean bargain case where all divorces are efficient, that is $V_{m}^{i}+V_{m}^{-i}<V_{d}^{i}+V_{d}^{-i}$. Here the critical joint shock is given by $\varphi^{*}=\varphi_{*}^{i}+\varphi_{*}^{-i}$, that is the sum of shocks below which divorces are unavoidable and above which marriages should to the joint benefit of the couple survive. This joint critical shock is simply determined by, $V_{m}^{i}+V_{m}^{-i}=V_{d}^{i}+V_{d}^{-i}$, that is $E V_{m}^{i}+E V_{m}^{-i}+\varphi_{*}^{i}+\varphi_{*}^{-i}=V_{d}^{i}+V_{d}^{-i}$, implying, whilst omitting to substitute in expressions (1) and (2): $\varphi^{*}=\varphi_{*}^{i}+\varphi_{*}^{-i}=V_{d}^{i}+V_{d}^{-i}-E V_{m}^{i}-E V_{m}^{-i}$. This is presented diagrammatically in Figure 2.

\section{Figure 2 here.}

The downward sloping line represents the combination of ex post shocks such that the individual shocks sum up to the critical one. The shaded area represents the incidence of efficient divorces which occur when the realisation of shocks are too adverse for the marriage to remain viable ${ }^{4}$. As expected, a simple comparison of Figures 1 and 2 illustrates that divorces occur more often in the absence of Coasean bargains and transfers.

Not wanting to restrict the analysis to either of the two cases depicted in Figure 1 and 2, the cases were analysed in turn starting with the non-Coasean case and then proceeding to the Coasean case next. This enabled a comparative study of the two frameworks. The following result demonstrated that though some differences were found, one should not overstate the argument as a lot of similarities were also found between the two cases. It should be noted that any factors that ceteris paribus decreased

\footnotetext{
3 With symmetric agents the marital survival probability is given by $1-\mathrm{p}=\frac{\left(\varphi^{H}-\varphi_{*}^{i}\right)\left(\varphi^{H}-\varphi_{*}^{-i}\right)}{\left(\varphi^{H}-\varphi^{L}\right)^{2}}$. Thus the divorce probability is $\mathrm{p}=1-\frac{\left(\varphi^{H}-\varphi_{*}^{i}\right)\left(\varphi^{H}-\varphi_{*}^{-i}\right)}{\left(\varphi^{H}-\varphi^{L}\right)^{2}}$. It follows that the probability of divorce is rising with the critical shock, since $\frac{d p}{d \varphi_{*}^{i}}=\frac{\left(\varphi^{L}-\varphi_{*}^{-i}\right)}{\left(\varphi^{H}-\varphi^{L}\right)^{2}}>0$. Any variable that reduces the critical shock will therefore have a positive effect on marital survival.

${ }^{4}$ Given the joint critical shock, the probability, p, of divorce follows by a simple geometric consideration of Figure 2 so that $\mathrm{p}=\frac{\frac{1}{2}\left(\varphi *-\varphi^{L}\right)^{2}}{\left(\varphi^{H}-\varphi^{L}\right)^{2}}$. Note that an increased intolerance of bad ex post realisations, that is an increase in the critical shock, will in effect increase the probability of a divorce since $\frac{d p}{d \varphi *}=\frac{\left(\varphi *-\varphi^{L}\right)}{\left(\varphi^{H}-\varphi^{L}\right)^{2}}>0$.
} 
(increased) the individual's critical shock $\varphi_{*}^{\mathrm{i}}$ in the non-Coasean case would also ceteris paribus have decreased (increased) the critical shock $\varphi^{*}$ in the Coasean case.

\section{Result 1.}

The critical shocks $\varphi_{*}^{i}$, in the non-Coasean, and $\varphi^{*}$, in the Coasean case, and therefore also the respective divorce rates, were declining with both own and spouse's innate ability in producing marriage specific products.

\section{The proof follows directly from Expression 35.}

Result 1 shows the effect of a higher ability in marriage specific production was to increase marital survival rates in both the non-Coasean and the Coasean case. This in turn implies that high marriage specific production ability, high innate love couples are less likely to seek a divorce. Marital ability has both a direct effect; that makes the individual less likely to seek a divorce, and an indirect externality effect; reducing the spouse's divorce propensity ${ }^{6}$. It should be noted, with ability being exogenously given, that investment in marital production has not been modelled in our study that concentrates on the ex post separation decision. Previous studies suggested nevertheless an under-investment in marriage specific capital (Baker and Jacobsen 2007; Vagstad 2001). This should therefore in the light of Result 1 translate into higher divorce rates. Note however arguments have been suggested that caring for the child as part of home production could yield custody rights ex post and give (females) more bargaining power (Brining and Allen 2000) thereby resulting in more divorces, but that the trend of changing to joint custody laws over the past few decades (Halla 2013) could reverse this tendency.

The non-Coasean individual spouse's choice of time spent in the labour market and marriage production in a continuing marriage is given by:

$$
\begin{aligned}
& \frac{\partial V_{m}^{i}}{\partial l_{m}^{i}}=\frac{w^{i}}{2} u^{\prime}\left(\frac{w^{i} l_{m}^{i}+w^{-i} l_{m}^{-i}}{2}\right)-v^{\prime}\left(1-l_{m}^{i}-m^{i}\right)-c_{l}^{i \prime}\left(l_{m}^{i}\right)=0 \\
& \frac{\partial V_{m}^{i}}{\partial m^{i}}=\frac{A^{i}}{2} v^{\prime}\left(\frac{A^{i} m^{i}+A^{-i} m^{-i}}{2}\right)-v^{\prime}\left(1-l_{m}^{i}-m^{i}\right)-c_{m}^{i}{ }^{\prime}\left(m^{i}\right)=0
\end{aligned}
$$

It follows that the leisure choice can be found trivially from conditions (4a), (4b) and the time constraint. Note the private optimum, as characterised by (4a) and (4b) does not necessarily maximise the joint marital surplus, which in the absence of any trading externalities is deemed equivalent to the social surplus. Indeed in order to

\footnotetext{
${ }^{5}$ The full detail of this proof as well as proofs of Results 2 6 in the paper are omitted for expositional purposes but can be found in Skåtun (2015).

${ }^{6}$ How couples' view of the value of household ability has altered over time and impacted on household shores has been the subject of a large literature, see for example Britt and Nazarinia-Roy (2014).
} 
investigate whether the privately optimal coincides with the jointly (social) efficient, consider now the maximisation of the social value of marriage survival, SV, which is merely given by the sum of the individual spouses' values of marriage, that is SV= $V_{m}^{i}+V_{m}^{-i}$. By recalling that spouses have identical utility functions, the conditions relating to individual i's socially optimal choices of market and marriage specific production follow:

$$
\begin{aligned}
& \frac{\partial S V}{\partial l_{m}^{i}}=w^{i} u^{\prime}\left(\frac{w^{i} l_{m}^{i}+w^{-i} l_{m}^{-i}}{2}\right)-v^{\prime}\left(1-l_{m}^{i}-m^{i}\right)-c_{l}^{i}\left(l_{m}^{i}\right)=0 \\
& \frac{\partial S V}{\partial m_{2}^{i}}=A^{i} v^{\prime}\left(\frac{A^{i} m^{i}+A^{-i} m^{-i}}{2}\right)-v^{\prime}\left(1-l_{m}^{i}-m^{i}\right)-c_{m}^{i}{ }^{\prime}\left(m^{i}\right)=0
\end{aligned}
$$

Expressions (4a), (4b), (5a) and (5b) directly imply lower than socially optimal private levels of effort in both sectors, as reflected by $l_{m}^{i}$ and $m^{i}$, when the marriage survives. This is the standard free riding under-provision result that arises in the public goods literature. In this case each partner in the marriage fails to take into account the positive externality their production has on their partner's utility. It reflects a tendency in marriages to work too little both in the market and at home. Though it is well known from the marriage literature that joint increases in contributions to the public good has been shown to yield Pareto improvements, see Konrad and Lommerud (2000), our model illustrates that this might also apply simultaneously to labour market and marital production contributions.

\section{Result 2.}

An increase in the spouse's wage would reduce (increase) one's own labour supply (home production) in the non-Coasean case.

Result 2 suggests quite intuitively that a married individual will substitute away from labour supply and into marital production when the wage of the spouse increases in the non-Coasean case. This provides a useful contrast to the spouse's wage effect in the Coasean case that will later be deduced from Result 4 below.

Turning now to the Coasean case, the employment and marital production are both subject to bargaining. With $\gamma_{\mathrm{i}}$ and $\left(1-\gamma_{\mathrm{i}}\right)$ representing the relative bargaining strengths of individual $\mathrm{i}$ and individual -i respectively, the Coasean Nash bargain is given by:



Thus the result below followed:

\section{Result 3.}


a) Married employment in the Coasean case exceeded married employment in the non-Coasean case.

b) Marriage production in the Coasean case exceeded marriage production in the non-Coasean case.

The result we find is perhaps not that surprising as the Coasean bargain can attain the socially optimum, whereas the non-Coasean outcome cannot. Thus our previous discussion with regard to the under-provision and free riding issues pertains to the non-Coasean case only. In the Coasean case in contrast agents put in more effort on average in order to make it work. The Coasean bargain implies some give and take so that each individual increases her/his effort, relatively to the purely selfish outcome, making the marriage more resilient. One way the Coasean bargain avoids the breakup of viable marriages is for individuals to work harder in the labour market. Another is to work harder within marriage production. This indicates that there are more routes to marital bliss than the theory of comparative advantage usually suggests. Indeed the paper illustrates that giving and receiving in a marriage takes several forms where contributions to and benefits from the marriage manifests themselves both through the level of labour market income and the production of marriage specific goods. This does not have to involve the specialisation that comparative advantage models are so often associated with. Indeed one can postulate, with differences in labour and marital productivity across marriages, that the degree of specialisation will vary across marriages. Thus in some marriages more equal division of marital tasks and labour market are used to sustain successful unions, whereas in others more traditional division of labour patterns are possible to make the marriage work.

\section{Result 4.}

Symmetry and ceteris paribus yielded, in the Coasean case:

i) With $\varphi^{\mathrm{i}}>\varphi^{-\mathrm{i}}$ it followed that $l_{m}^{i}>l_{m}^{-i}$ and that $m^{i}>m^{-i}$.

ii) With $s^{i}<S^{-i}$ it followed that $l_{m}^{i}>l_{m}^{-i}$ and that $m^{i}>m^{-i}$.

iii) With $\mathrm{w}^{\mathrm{i}}>\mathrm{w}^{-\mathrm{i}}$ it followed that $l_{m}^{i}<l_{m}^{-i}$ and that $m^{i}<m^{-i}$ when $\mathrm{s}^{\mathrm{i}}>1 / 2$.

iv) With $\mathrm{w}^{\mathrm{i}}>\mathrm{w}^{-\mathrm{i}}$ it followed that $l_{m}^{i} \leq l_{m}^{-i}$ and that $m^{i} \leq m^{-i}$ when $\mathrm{s}^{\mathrm{i}}=1 / 2$ and $l_{m}^{i} \leq l_{d}^{i}$ and $l_{m}^{-i} \leq l_{d}^{-i}$

In the Coasean case it follows from part i) that if individual i are faced with a more favourable ex post realisation of marriage than individual $-i$, that individual i will increase efforts both at home as well as in the labour market. This result seems intuitive since an increase in an individual's value of marriage will induce her/him to strive to 
ensure the marriage has the best possibilities of surviving. A reduction in the value of marriage can likewise be used as bargaining leverage by a negatively affected individual, given the now more credible threat to leave, eliciting a higher effort from that individual's partner, who works harder in the market and at home in order to save the marriage. In other words, as long as it is in the joint benefit of the spouses to stay married, Coasean bargaining implies an arrangement can be found so that the partner who gains the most sacrifices the most in order for the marriage to survive.

Part ii) is equally straightforward to interpret as an increase in the divorce settlement share of the couple's joint labour income increases the outside option of the individual. This creates a leverage that can be exploited in the bargain.

Part iii) suggests that the individual with the largest wage will if he/she also receives the lion share in the divorce settlement labour market put less effort into labour market and marriage productive activities. Since part ii) implies a higher share in the ex post division of household income increases the individual bargaining position and a higher own wage will do the same, part iii) of the result follows. The person with the lowest wage and the lowest ex post share, on the other hand, is doubly unlucky when the divorce occurs, yielding a weak bargaining situation forcing her/him to exert higher effort within the marriage. Thus inequitable divorce shares do not only affect the individuals should a divorce occur, it also affects the individuals within the marriage.

Part iv) suggests a similar effect to part iii) is obtained with equal shares ex post if the divorced labour supply exceeds marital labour supply. A wage increase in such a situation would benefit the individual more in divorce than whilst married. Thus an increase in labour market productivity strengthens the bargaining position of the individual causing the negative correlation between labour supply and wages. Similarly a wage increase will cause the spouse to work more, in sharp contrast to the nonCoasean case where a spouse's wage increase will be accompanied by a reduction in labour supply. This therefore provides a testable hypothesis to distinguish Coasean bargains from hedonistic non-cooperative behaviour.

Whereas the actual working time is jointly determined with time allocated to marriage specific production whilst married, the divorcee is freed from this latter activity. Comparing pre and post-divorce labour market outcomes yielded unambiguous results in the non-Coasean case:

\section{Result 5.}

If $\mathrm{s} \leq 1 / 2$ then $l_{d}^{i}>l_{m}^{i}$ in the Non-Coasean case.

That spouses, who receive the lowest share (or equal share) of the ex post divorce income, work more if divorced than if married is in the non-Coasean case caused 
by two effects. First, the marginal utility of market production has increased (or stayed constant if $s^{i}=1 / 2$ ) as the divorcee gets less (or the same) of the joint income when divorced than when married. Thus the divorcee tends to work more (or not change her/his working time). Second, as divorces are associated with the complete fall off in joint marital production, it follows that the time an individual spends on her/his own will increase after a divorce. This causes the marginal utility of leisure to fall, which in turn tends to suggest that the divorcee substitutes away from leisure into market productive activities. The net effect of both these two effects is therefore to work more when $\mathrm{s} \leq 1 / 2$.

Result 5 cannot be generalised to the case when $s^{i}>1 / 2$. This is due to the reversal in the sign of the first of the effects mentioned above. In other words, for individuals who receive a share $s^{i}>1 / 2$, the marginal utility of consumption of market goods falls, when moving to the divorced state. This yields a negative impact on labour supply. However, becoming divorced will reduce the marginal utility of leisure regardless of $s^{i}$ and will therefore tend to increase the amount of labour supplied. Whether the overall impact of divorce on labour supply is positive or negative, when $s^{i}>1 / 2$, depends on the relative strength of the two opposing forces. Thus it is a matter that is impossible to ex ante predict without further restriction.

Comparing Results 5 and 3 yields some interesting conclusions and illustrates that the result of Result 5, valid in the non-Coasean case, does not necessarily translate to the Coasean case. Recall that Result 3 states that a Coasean bargain tends to yield higher labour market activity whilst married than its non-Coasean counterpart. It is therefore possible that the Coasean bargaining could induce higher labour supply within a marriage than in a divorce. Thus, while the move into a divorce state will free up more "pure" leisure time, inducing a substitution effect into labour, the Coasean transfers provide a reason for the spouse to stay within the marriage to countervail this substitution effect. Hence, there is a possibility that Coasean trading partners, who are induced to work hard in order to keep their marriage from collapsing, will with a termination of their marriage work less. This realisation provides yet another way to examine whether or not marriages are subject to Coasean bargains or not. A finding that spouses work less after a marriage under equitable sharing rules would in the context of this model suggest that marriages are governed by Coasean bargains, whereas the opposite finding would exclude neither of the two cases. Whilst we may argue that females have tended to receive a lower share of marital income after a dissolution, and that females have tended to work more in the divorced state (Gray 1998; Johnson and Skinner 1986), it is also true that females have tended to work more over the recent 
decades or so (Tamborini et al. 2012) when females have been treated more equitable. As such it can be used only as weak evidence for non-Coasean behaviour.

Some further caution is needed however, as either partner may work less if the shock is severe enough to trigger a Coasean efficient divorce, that is where no Coasean side payment exists to enable a mutual beneficial marriage continuation. Indeed such a realisation could exasperate conflict between the parties, as argued by DeMaris (2000), and thereby hasten the divorce. Though there has been evidence that females have worked more in anticipation of divorce (Johnson and Skinner 1986; Özcan and Breen 2012; Sen 2000), which could be taken as an indication that they have worked harder in a Coasean sense to save the marriage, females also have been found to work less in home production (Hewitt et al. 2013) before a divorce. Whilst the latter could be taken as evidence for non-Coasean behaviour it may not have precluded Coasean bargains as it may simply have indicated an inevitable Coasean efficient ending of the marriage making any additional effort futile.

The paper has so far not investigated the impact of labour market ability, as measured by the wage, has on the propensity to divorce. This is as such important since it is well known that that the risk of divorce has been shown to be stronger for lower socioeconomic groups (Sweeney 2002) and the more educated (Martin 2006; Raley and Bumpass 2003) who have tended to be paid more ${ }^{7}$. The effect is critically dependent on two factors; first, the ex post sharing rule $s^{i}$ of joint labour income in the event of a divorce and second on the labour supply variation across marital status. Through Results 3 and 5 more light is shone on the latter of these factors facilitating a more thorough investigation of the relationship between labour market productivity and marital breakup.

Under reasonable assumptions we found:

\section{Result 6.}

Part 1: An increase in one's own labour market ability would;

a) have no effect on $\frac{\partial \varphi_{i}^{*}}{\partial w^{i}}$ in the case of $s^{\mathrm{i}}=1 / 2$ when the individuals labour supply was invariant to marital status (that is $l_{d}^{i}=l_{m}^{i}$ ), but would increase (decrease) $\frac{\partial \varphi_{i}^{*}}{\partial w^{i}}$ when $l_{d}^{i}>l_{m}^{i}\left(l_{d}^{i}<l_{m}^{i}\right)$

\footnotetext{
${ }^{7}$ Whilst it is noted that the model has little to say about divorces across different age groups and the continuing trend of older marriages breaking down, as was demonstrated by Brown and Lin (2012), it should be noted that wages do tend to increase with tenure and age. Thus Result 6 and the discussion that follows may have some tentative conclusions for this age group.
} 
b) decrease $\frac{\partial \varphi_{i}^{*}}{\partial w^{i}}$ in the case of $\mathrm{s}^{\mathrm{i}<1 / 2}$ when $l_{d}^{i} \leq l_{m}^{i}$.

c) increase $\frac{\partial \varphi_{i}^{*}}{\partial w^{i}}$ in the case of $\mathrm{s}>1 / 2$ when $l_{d}^{i} \geq l_{m}^{i}$.

Part 2: An increase in the spouse's labour market ability would;

a) have no effect on $\frac{\partial \varphi_{i}^{*}}{\partial w^{-i}}$ in the case of $s^{\mathrm{i}}=1 / 2$ when the individual's labour supply was invariant to marital status (that is $l_{d}^{i}=l_{m}^{i}$ ),but would decrease (increase) $\frac{\partial \varphi_{i}^{*}}{\partial w^{-i}}$ when $l_{d}^{i}>l_{m}^{i}\left(l_{d}^{i}<l_{m}^{i}\right)$

b) decrease $\frac{\partial \varphi_{i}^{*}}{\partial w^{-i}}$ when $\mathrm{s}^{\mathrm{i}<1 / 2}$ and $l_{d}^{i}>l_{m}^{i}$, ambiguous otherwise.

c) increase $\frac{\partial \varphi_{i}^{*}}{\partial w^{-i}}$ when $\mathrm{s}^{\mathrm{i}>1 / 2}$ and $l_{d}^{i}<l_{m}^{i}$, ambiguous otherwise.

Result 6 makes it immediately apparent that there are few conclusions to be made with regards to the impact of labour market ability/wage on the married couples' overall divorce probability, with an inequitable sharing rule after a divorce. In order to proceed further consider therefore the equitable sharing rule. Here a rich picture emerged as is reflected in Table 1.

\section{Table 1 here.}

Though Table 1 distinguishes between Coasean and non-Coasean divorces, the effects of labour market ability on the overall propensities to divorce were most often observably equivalent between Coasean and non-Coasean behaviour. Consider a situation where one individual's propensity to divorce increases in response to higher labour market ability, $\frac{\partial \varphi_{i}^{*}}{\partial w^{i}}>0$, whereas her/his spouse's propensity to seek a divorce decreases $\frac{\partial \varphi_{-i}^{*}}{\partial w^{i}}<0$. There is then an indeterminate effect on the overall divorce probability in both the non-Coasean and Coasean instances. Similarly, if individual propensities to divorce of both spouses fall (increase) in response to labour market ability increases then the overall divorce probability will fall (increase) both with and without Coasean transfers. 
In Cases 1, 2, 4, and 5 both Coasean and non-Coasean bargains are possible ${ }^{8}$. However, following Result 5 non-Coasean interactions were not applicable in the cases where an individual worked more in marriage than after divorce. Thus Cases 7-9 can only occur in Coasean bargains, since the individual, whose labour market ability was increasing, ended up working less in divorce than in marriage. Non-Coasean behaviour could also not occur in Cases 3, 6, and 9 where the spouse of the individual reduced her/his labour supply in response to a divorce.

Traditional gender role models saw the male as the main family breadwinner with a wife working less than her husband. Though this division of labour within a family has weakened over time, it still persists. Whether this is because of the perseverance of stereotypical gender roles, merely a reflection of family optimisation or a combination of both is not clear. Booth and van Ours (2008) suggested married couple satisfaction with hours of work and job satisfaction was highest when the male worked full-time and the female worked part-time. If one then takes as the premise found in the literature that many workers have been constrained by working time, (see Bell et al. 2012 for a discussion), it may very well be that there are a number of marriages where a full time working husband would find it difficult to change his working time after a divorce, whereas a part time working female may find it easier to increase her working hours. This is the situation described under Cases 2 and 4 in Table 1 . These cases illustrates that a marriage consisting of a full time working and a part time working spouse may be more likely to survive if the wage of the full time worker increases and the part time working spouse's wage decreases. It is therefore possible that such circumstances give support to the adage that full time males resent their wives making investments that increase their wage in the labour market. These conditions are consistent and may help explain why young males' preferences for stereotypical work division persist whilst females give more emphasis to non-monetary aspects, as was found by Fortin (2008), and why part time work by females has been associated with a downgrading of skills, (Connolly and Gregory 2008). Cases 2 and 4 are further consistent with assortative matching (as for instance argued by Burdett and Coles 1998). It also aligns well to the argument (Becker 1991) where comparative advantage tended to suggest specialisation of tasks with one partner working more in the labour market and the other producing more home goods to the benefit of successful

\footnotetext{
8 It is assumed for Case 1 only that the individuals are in fixed hour contract employment where they could not alter working hours following. It should however be noted from Result 5 that Case 1 is not be applicable in the non-Coasean case if individuals can freely change working hours since both individuals would want to reduce labour supply after a divorce.
} 
marriages. It finally gives theoretical support to evidence (Hoffman and Duncan 1995) of a negative correlation between the probability of divorce and a wife's wage.

Nevertheless one must not overstate the assortative matching effect. For other models the division of labour may also work well for a marriage. For instance, it is interesting to note Cases 2 and 4 also imply that increasing both spouses' wages have an ambiguous effect on the overall divorce probability. Empirical investigations have shed more light on the issue, (Whittington and Alm 1997), who found that both own and spouse's after tax income increases reduced the dissolution of marriages. Hence such evidence could in the light of our model suggest there are more routes to marital bliss than assortative matching.

There are also other cases in Table 1 to evaluate. Consider the instance where both spouses work full time and cannot alter hours worked. This is arguably applicable to Case 1, where under equitable division rules any change in labour market remuneration will have no effect on divorce. Such a case may have become increasingly more applicable with time with both an increase in equitable post-divorce sharing and an increase in female labour participation (full-time work) over time.

The remaining cases are all inconsistent with non-Coasean behaviour. Though all these cases will not be discussed extensively a couple are worth a brief mention. Cases 3 and 7 are cases where only one individual cuts their labour supply after a divorce. This might encompass situations where one spouse who works hard within a marriage to make it work, finds it optimal to reduce her/his labour supply in the event of a divorce. In Case 3, the spouse cuts labour supply after a divorce. The own propensity to seek a divorce remains unchanged to an increase in own labour market ability but the spouse's individual divorce propensity increases thus increasing the overall divorce probability. In Case 7 it is own labour supply that falls after the failure of the marriage, leading thus to a fall in the probability of divorce as own ability increases. Cases 6 and 8 are similar in intuition to Cases 3 and 7 respectively. Finally Cases 5 and 9 relate to marriages where both individuals either increase or reduce labour supply after a divorce. Any change in labour market ability for such individuals will have an indeterminate effect on overall divorce propensities.

There is a plethora articles that have dealt with labour supply and marriage. The evidence has been mixed. Some argued that higher female wages (van der Klaauw 1996) and greater female labour force participation (Johnson and Skinner 1986; Ozcan and Breen 2012) increased the propensity to divorce. Others (Sayer and Bianchi 2000; Mueller 2005) found no effect of female labour supply. There are also articles that argued that financial strain has threatened marriage (Bridges and Disney 2016). Thus it 
is not necessarily clear from an empirical point of view whether working more in the labour market within marriage would yield higher or lower divorce rates. However no empirical difference has been found in divorce risk between spouses with egalitarian views and work arrangements and spouses with more traditional views and division of labour (Olah and Gähler 2014) supporting our result that different models work sharing arrangements within marriages could work to promote marital survival.

\section{Conclusion.}

Though the Coasean and the non-Coasean cases are similar in many ways, there is more to divide them than the mere effect that follows the introduction of unilateral divorce laws. This paper has sought to shed further light on what identifies one case from another. Perhaps one of the most dramatic results of the paper is the reaction of an individual to the increase in her/his spouse's wage. In the non-Coasean case this will lead to a substitution away from own labour supply, whilst in the Coasean case there is instead a positive response in both own labour supply and marital production. Starting from the premise that Coasean bargains facilitate marital survival it is now apparent that there are more ways to avoid marital breakdown than the theory of comparative advantage would seem to suggest. For whereas that theory proposes specialisation in tasks should enhance a marriage, thus making breakup less likely, our model shows that Coasean bargains lead to more effort in both the labour market as well as in marital production. This co-movement is only possible by relaxing the all-pervasive assumption that time is simply divided into work and leisure to instead introduce a new tripartite treatment of time, missing from previous literature, where time is now divided into the activities of labour production, marital production and leisure.

Whereas by construction, there is an absence of reactions to adverse shocks in the non-Coasean case, no such failures materialise in the Coasean case, where the analysis produces several a priori unknown but ex post intuitive results. One of the more notable of these is the effect that shows it is the partner who experiences less adverse shock who works harder in order to save the marriage. It is likewise worth noting that individuals with higher shares in income after a divorce can extract more from their spouses by getting them to contribute more within the marriage. Higher own wages tend to induce higher effort levels from the spouse, more concerned about marital break-up, though this result is dependent on the judicial sharing rule following a divorce. 
The results presented here further demonstrate how legal structures within family law play an important role for outcomes relating to labour market decisions. The consideration of how property rights, to marital income during a marriage and after a divorce, affect the marriage outcome and divorce decision has been a neglected area of research. This paper seeks in part to rectify this. Though all our results are not contingent on equal treatment with regards to income sharing within marriage and divorce, many are conditional on this assumption. It is in this respect worth emphasising that this condition does not need to mean that the share of income attributed to any individual in marriage and divorce is always necessarily 50\%, but rather that the share an individual receives is insensitive to marital status. This wider interpretation covers a range of legal jurisdictions. Furthermore the more narrow 50-50 split assumption is less restrictive than what previously might have been the case, as there has been a trend in legal practices and social convention that produce a greater emphasis on the equal treatment of individuals across gender divides.

It should finally be noted that this paper has some limitations that if exploited can form the basis for future work. For instance, the paper has not devoted any analysis to the importance of children and differences in gender. Further theoretical explorations are as such needed to investigate how these factors interact with Coasean bargains and non-Coasean behaviour. Investigating Coasean bargaining in the presence of an explicit modelling of matching in the remarriage market is an additional route of research that is likewise of potential interest. This paper has not provided any empirical investigations. It is instead a theoretical exploration of Coasean and non-Coasean behaviour within marriage providing a framework of predictions that can be exploited in future empirical investigations.

\section{References:}

Agnew, J. R., Anderson, L. R., Gerlach, J. R., \& Szykman, L. R. (2008). Who chooses annuities? An experimental investigation of the role of gender, framing, and defaults. American Economic Review, 98, 418-442. doi: 10.1257/aer.98.2.418

Akerlof, G. A., \& Kranton, R. E. (2000). Economics and identity. Quarterly Journal of Economics, 115, 715-753. doi: 10.1162/003355300554881

Alesina, A., Giuliano, P., Bisin, A., \& Benhabib, J. (2011). Preferences for redistribution. In J. Benhabib, A. Bisin \& M. O. Jackson (Eds.), Handbook of Social Economics. (pp. 93-132) Amsterdam, North Holland.

Allen, D. W. (1992). Marriage and divorce: Comment. American Economic Review, 82, 679-685. Retrieved from http://www.jstor.org/stable/2117332 
Amato, P. R. (2010). Research on divorce: Continuing trends and new developments. Journal of Marriage and Family, 72, 650-666. doi:10.1111/j.17413737.2010.00723.x

Baker, M. J., \& Jacobsen, J. P. (2007). Marriage, specialization, and the gender division of labor. Journal of Labor Economics, 25, 763-793. Retrieved from http://www.jstor.org/stable/10.1086/522907

Becker, G. S. (1973). A theory of marriage: Part I. Journal of Political Economy, 81, 813846. Retrieved from http://www.jstor.org/stable/1831130

Becker, G. S. (1974). A theory of marriage: Part II. Journal of Political Economy, 82, SllS26. Retrieved from http://www.jstor.org/stable/1829987

Becker, G. S. (1991). A treatise on the family. Harvard University Press, Cambridge, Massachusetts, US.

Becker, G. S., Landes, E. M., \& Michael, R. T. (1977). An economic analysis of marital instability. Journal of Political Economy, 85, 1141-1187. Retrieved from http://www.jstor.org/stable/1837421

Bell, D., Otterbach, S., \& Sousa-Poza, A. (2012). Work hours constraints and health. Annals of Economics and Statistics, No. 105/106, 35-54. Retrieved from http://www.jstor.org/stable/23646455

Bergstrom, T. C. (1997). A survey of theories of the family. In M. R. Rosenzweig \& 0. Stark (Eds.), Handbook of Population and Family Economics, (pp. 21-79), Elsevier Publisher.

Booth, A. L., \& van Ours, J. C. (2008). Job satisfaction and family happiness: The parttime work puzzle. Economic Journal, 118, F77-F99. Retrieved from http://www.jstor.org/stable/20108792

Borghans, L., Golsteyn, B. H. H., Heckman, J. J., \& Meijers, H. (2009). Gender differences in risk aversion and ambiguity aversion. Journal of the European Economic Association, 7, 649-658. doi: 10.1162/JEEA.2009.7.2-3.649

Bowles, H. R., Babcock, L., \& McGinn, K. L. (2005). Constraints and triggers: Situational mechanics of gender in negotiation. Journal of Personality and Social Psychology, 89, 951-965. http://dx.doi.org/10.1037/0022-3514.89.6.951

Bridges, S., \& Disney, R. (2016). Household finances, income shocks, and family separation in Britain. Economic Inquiry, 54, 698-718. doi:10.1111/ecin.12259

Brining, M. F., \& Allen, D. W. (2000). These boots are made for walking: Why most divorce filers are women. American Law and Economics Review, 2, 126-169. doi: 10.1093/aler/2.1.126

Britt, S. L. \& Nazarinia-Roy, R. R. (2014). Relationship quality among young couples from an economic and gender perspective. Journal of Family and Economic Issues, 35, 241-250. doi:10.1007/s10834-013-9368-x

Brown, S. L., \& Lin, I. F. (2012). The gray divorce revolution: Rising divorce among middle-aged and older adults, 1990-2010. Journals of Gerontology Series B: Psychological Sciences and Social Sciences, 67, 731-741. doi:10.1093/geronb/gbs089.

Browning, M., \& Chiappori, P. A. (1998). Efficient intra-household allocations: A general characterization and empirical tests. Econometrica, 66, 1241-1278. Retrieved from http://www.jstor.org/stable/2999616

Burdett, K. \& Coles, M. G. (1998). Separation cycles. Journal of Economic Dynamics and Control, 22, 1069-1090. doi:10.1016/S0165-1889(97)00101-2

Chen, Z., \& Woolley, F. (2001). A Cournot-Nash model of family decision making. Economic Journal, 111, 722-748. Retrieved from http://www.jstor.org/stable/798410

Chiappori, P. A., Fortin, B., \& Lacroix, G. (2002). Marriage market, divorce legislation, and household labor supply. Journal of Political Economy, 110, 37-72. Retrieved from http://www.jstor.org/stable/10.1086/324385 
Clark, S. (1999). Law, property, and marital dissolution. Economic Journal Conference Papers, 109, C41-C54. Retrieved from http://www.jstor.org/stable/2565905

Clements, M. L., Stanley, S. M., \& Markman, H. J. (2004). Before they said "I do": Discriminating among marital outcomes over 13 years. Journal of Marriage and Family, 66, 613 - 626. doi: 10.1111/j.0022-2445.2004.00041.x

Coase, R. H. (1960). The problem of social cost. The Journal of Law and Economics, 3, 144. Retrieved from http://www.jstor.org/stable/724810

Connolly, S., \& Gregory, M. (2008). Moving down: Women's part-time work and occupational change in Britain 1991-2001. Economic Journal, 118, F52-F76. Retrieved from http://www.jstor.org/stable/20108791

Croson, R., \& Gneezy, U. (2009). Gender differences in preferences. Journal of Economic Literature, 47, 448-474. doi: 10.1257/jel.47.2.448

Davis, S. N., \& Wills, J. B. (2015).Theoretical explanations amid social change: A content analysis of housework research (1975-2012). Journal of Family Issues, advanced online publication. doi: 10.1177/0192513X13513020

DeMaris, A. (2000). Till discord do us part: The role of physical and verbal conflict in union disruption. Journal of Marriage and the Family, 62, 683-692. doi: 10.1111/j.1741-3737.2000.00683.x

Dew, J., \& Wilcox, W. B. (2011). If Momma ain't happy: Explaining declines in marital satisfaction among new mothers. Journal of Marriage and Family, 73, 1-12. doi: 10.1111/j.1741-3737.2010.00782.x

Fortin, N. M. (2008). The gender wage gap among young adults in the united states. The importance of money versus people. Journal of Human Resources, 43, 884-918. Retrieved from http://www.jstor.org/stable/40057374

Friedberg, L. (1998). Did unilateral divorce raise divorce rates? Evidence from panel data. American Economic Review, 83, 608-627. Retrieved from http://www.jstor.org/stable/116852

Geddes, R., \& Lueck, D. (2002). The gains from self-ownership and the expansion of women's rights. American Economic Review, 92, 1079-1092. Retrieved from http://www.jstor.org/stable/3083297

González, L., \& Viitanen, T. K. (2009).The effect of divorce laws on divorce rates in Europe. European Economic Review, 53, 127-138. doi:10.1016/j.euroecorev.2008.05.005

Gray, J. S. (1998). Divorce-law changes, household bargaining, and married women's labor supply. American Economic Review, 88, 628-642. Retrieved from http://www.jstor.org/stable/11685

Halla, M. (2013).The effect of joint custody on family outcomes. Journal of the European Economic Association, 11, 278-315. doi: 10.1111/jeea.12003

Hall, J. H., \& Fincham, F. D. (2006). Relationship dissolution after infidelity. In M. Fine \& J. Harvey (Eds.), Handbook of divorce and relationship dissolution (pp. 153-168). Hillsdale, NJ: Erlbaum

Hartog, J., Ferrer-i-Carbonell, A., \& Jonker, N. (2002). Linking measured risk aversion to individual characteristics. Kyklos, 55, 3-26. doi: 10.1111/1467-6435.00175

Hersch, J., \& Stratton, L. S. (2000). Household specialization and the male marriage wage premium. Industrial and Labor Relations Review, 54, 78-94. Retrieved from http://www.jstor.org/stable/2696033

Hewitt, B., Haynes, M., \& Baxter, J. (2013). Relationship dissolution and time on housework. Journal of Comparative Family Studies, 44, 327-340. Retrieved from http://www.jstor.org/stable/23644605

Hoffman, S. D., \& Duncan, G. J. (1995). The effect of income, wages and AFDC benefits on marital disruption. Journal of Human Resources, 30, 19-41. Retrieved from http://www.jstor.org/stable/146189 
House of Lords (2000). Judgments - White v. White (Conjoined appeals). Retrieved from http://www.publications.parliament.uk/pa/ld199900/ldjudgmt/jd001026/whi te-1.htm

House of Lords (2006). Opinions of the Lords of appeal for judgment in the cause: Miller (Appellant) $v$. Miller (Respondent); McFarlane (Appellant) $v$. McFarlane (Respondent). HOUSE OF LORDS SESSION 2005-06[2006] UKHL24 on appeal from: [2005] EWCA Civ 984 and [2004] EWCA Civ 872. Retrieved from http://www.publications.parliament.uk/pa/ld200506/ldjudgmt/jd060524/mill $-1 . h t m$

Johnson, W. R., \& Skinner, J. (1986). Labor supply and marital separation. American Economic Review, 76, 455-469. Retrieved from http://www.jstor.org/stable/1813362

Konrad, K. A., \& Lommerud, K. E. (2000). The bargaining family revisited. Canadian Journal of Economics / Revue canadienne d'Economique, 33, 471-487. Retrieved from http://www.jstor.org/stable/2667441

Lawrence, E., \& Bradbury, T. N. (2001). Physical aggression and marital dysfunction: A longitudinal analysis. Journal of Family Psychology, 15, 135-154. doi: 10.1037//0893-3200.15.1.135

Lommerud, K. E. (1989). Marital division of labor with risk of divorce: The role of "voice" enforcement. Journal of Labor Economics, 7, 113-127. Retrieved from http://www.jstor.org/stable/2534992

Lundberg, S. J. \& Pollak, R. A. (1993). Separate spheres bargaining and the marriage market. Journal of Political Economy, 101, 988-1010. Retrieved from http://www.jstor.org/stable/213856

Lundberg, S. J. \& Pollak, R. A. (1994). Noncooperative bargaining models of marriage. American Economic Review, Papers and Proceedings, 84, 132-137. Retrieved from http://www.jstor.org/stable/2117816

Manser, M., \& Brown, M. (1981). Marriage and household decision-making: A bargaining analysis. International Economic Review, 21, 31-44. Retrieved from http://www.jstor.org/stable/2526238

Martin, S. P. (2006). Trends in marital dissolution by women's education in the United States. Demographic Research, 15, 537-560. doi:10.4054/DemRes.2006.15.20

Matouschek, N., \& Rasul, I. (2008). The Economics of the marriage contract: Theories and evidence. Journal of Law and Economics, 51, 59-110. Retrieved from http://www.jstor.org/stable/10.1086/588596

McElroy, M. B., \& Horney, M. J. (1981). Nash-bargaining household decisions: Toward a generalisation of the theory of demand. International Economic Review, 22, 33349. Retrieved from http://www.jstor.org/stable/2526280

McKinnish, T. G. (2007). Sexually integrated workplaces and divorce: Another form of on-the-job search. Journal of Human Resources, 42, 331-52. Retrieved from http://www.jstor.org/stable/40057308

Mortensen, D.T. (1988). Matching: Finding a partner for life or otherwise. American Journal of Sociology, 94, S215-S240. Retrieved from http://www.jstor.org/stable/2780247

Mueller, R. E. (2005). The effect of marital dissolution on the labour supply of males and females: Evidence from Canada. Journal of Socio-Economics 34, 787-809. doi:10.1016/j.socec.2005.07.023

Ogolsky, B. G., Surra, C. A., \& Monk, J. K. (2015). Pathways of commitment to wed: The development and dissolution of romantic relationships. Journal of Marriage and Family, advanced online publication. doi: 10.1111/jomf.12260

Oláh, L. Sz., \& Gähler, M. (2014). Gender equality perceptions, division of paid and unpaid work, and partnership dissolution in Sweden. Social Forces, Advanced online publication, doi: 10.1093/sf/sou066 
Özcan, B., \& Breen, R. (2012). Marital instability and female labor supply. Annual Review of Sociology, 38, 463-481. doi:10.1146/annurev-soc-071811-145457

Parkman, A. M. (2004). The importance of gifts in marriage. Economic Inquiry, 42, 48395. doi: $10.1093 / \mathrm{ei} / \mathrm{cbh} 075$

Peters, H. E. (1986). Marriage and divorce: Informational constraints and private contracting. American Economic Review, 76, 437-54. Retrieved from http://www.jstor.org/stable/1813361

Peters, H. E. (1992). Marriage and divorce: Reply. American Economic Review, 82, 686693. Retrieved from http://www.jstor.org/stable/2117333

Peters, M., \& Siow, A. (2002). Competing premarital investments. Journal of Political Economy, 110, 592-608. Retrieved from http://www.jstor.org/stable/10.1086/339729

Previti, D., \& Amato, P. R. (2004). Is infidelity a cause or a consequence of poor marital quality? Journal of Social and Personal Relationships, 21, 217-230. doi: $10.1177 / 0265407504041384$

Rainer, H. (2007). Should we write prenuptial contracts? European Economic Review, 51, 337-363. doi:10.1016/j.euroecorev.2006.02.001

Raley, R. K., \& Bumpass, L. L. (2003). The topography of the divorce plateau: Levels and trends in union stability in the United States after 1980. Demographic Research, 8, 245-260. doi:10.4054/DemRes.2003.8.8

Rasul, I. (2006). Marriage markets and divorce laws. Journal of Law, Economics and Organisation, 22, 30-69. Retrieved from http://www.jstor.org/stable/3555033

Rupert, P., Rogerson, R., \& Wright, R. (2000). Homework in labor economics: Household production and intertemporal substitution. Journal of Monetary Economics, 46, 557-579. doi:10.1016/S0304-3932(00)00038-6

Sayer, L. C., \& Bianchi, S. M. (2000). Women's economic independence and the probability of divorce: a review and reexamination. Journal of Family Issues, 21, 906-943. doi: 10.1177/019251300021007005

Sen, B. (2000). How important is anticipation of divorce in married women's labor supply decisions? An intercohort comparison using NLS data. Economics Letters, 67, 209-216. doi:10.1016/S0165-1765(99)00259-1

Siow, A. (1998). Differential fecundity, markets, and gender roles. Journal of Political Economy, 106, 334-354. Retrieved from http://www.jstor.org/stable/10.1086/250011

Skåtun, J. D. (2015). Bargaining on your spouse: Coasean and non-Coasean behaviour within marriage. Discussion Paper in Economics, no. 2 , vol. 15 , University of Aberdeen Business School. Retrieved from http://aura.abdn.ac.uk/bitstream/2164/5715/1/DP_2015_2.pdf?_ga=1.483795 56.367192834 .1360251199

Smith, I. (2003). The law and economics of marriage contracts. Journal of Economic Surveys, 17, 201-226. doi: 10.1111/1467-6419.00193

Smith, I. (2007). Property division on divorce with inequity aversion. International Review of Law and Economics, 27, 111-128. doi:10.1016/j.irle.2007.06.006

Sweeney, M. M. (2002). Two decades of family change: The shifting economic foundations of marriage. American Sociological Review, 67, 132-147. Retrieved from http://www.jstor.org/stable/3088937

Tamborini, C. R., Iams, H. M., \& Reznik, G. L. (2012). Women's earnings before and after marital dissolution: Evidence from longitudinal earnings records matched to survey data. Journal of Family Economic Issues, 33, 69-82. doi: 10.1007/s10834011-9264-1

Tamborini, C. R., Couch, K. A., \& Reznik, G. L. (2015). Long-term impact of divorce on women's earnings across multiple divorce windows: A life course perspective. Advances in Life Course Research, 26, 44-59. doi:10.1016/j.alcr.2015.06.001 
Thornton, A., \& Young-DeMarco, L. (2001). Four decades of trends in attitudes toward family issues in the United States: The 1960s through the 1990s. Journal of Marriage and Family, 63, 1009-1037. doi: 10.1111/j.1741-3737.2001.01009.x

Vagstad, S. (2001). On the private incentives to acquire household production skills. Journal of Population Economics, 14, 301-312. Retrieved from http://www.jstor.org/stable/20007763

van Damme, M., Kalmijn, M., \& Uunk, W. (2009). The employment of separated women in Europe: Individual and institutional determinants. European Sociological Review, 25, 183-197. doi:10.1093/esr/jcn042

van der Klaauw, W. (1996). Female labour supply and marital status decisions: A lifecycle model. Review of Economic Studies, 63, 199-235. Retrieved from http://www.jstor.org/stable/2297850

Weiss, Y., \& Willis, R. J. (1997). Match quality, new information, and marital dissolution. Journal of Labor Economics, 15, S293-S329. Retrieved from http://www.jstor.org/stable/2535409

Whittington, L. A., \& Alm, J. (1997). Til death or taxes do us part - The effect of income taxation on divorce. Journal of Human Resources, 32, 388-412. Retrieved from http://www.jstor.org/stable/146220

Wolfers, J. (2006). Did unilateral divorce raise divorce rates? A reconcilliation and new results. American Economic Review, 96, 1805-1820. Retrieved from http://www.jstor.org/stable/30034996 
Table 1. The effect of labour market ability increases under equitable sharing.

\begin{tabular}{|l|l|l|l|l|l|l|}
\hline Case & $\begin{array}{l}\text { Sign of } \\
l_{d}^{i}-l_{m}^{i}\end{array}$ & $\begin{array}{l}\text { Sign of } \\
l_{d}^{-i}-l_{m}^{-i}\end{array}$ & $\begin{array}{l}\text { Sign } \\
\text { of } \\
\frac{\partial \varphi^{i}}{\partial w_{i}}\end{array}$ & $\begin{array}{l}\text { Sign } \\
\text { of } \\
\frac{\partial \varphi^{-i}}{\partial w_{i}}\end{array}$ & $\begin{array}{l}\text { Non Coasean } \\
\text { Divorce } \\
\text { Propensity }\end{array}$ & $\begin{array}{l}\text { Coasean } \\
\text { Divorce } \\
\text { Propensity }\end{array}$ \\
\hline 1 & 0 & 0 & 0 & 0 & 0 & 0 \\
\hline 2 & 0 & + & 0 & - & - & - \\
\hline 3 & 0 & - & 0 & + & NA & + \\
\hline 4 & + & 0 & + & 0 & + & + \\
\hline 5 & + & + & + & - & $?$ & $?$ \\
\hline 6 & + & - & + & + & NA & + \\
\hline 7 & - & 0 & - & 0 & NA & $\sim$ \\
\hline 8 & - & + & - & - & NA & $\sim$ \\
\hline 9 & - & - & - & + & NA & $?$ \\
\hline
\end{tabular}

Figure 1. The non-Coasean divorce propensity.

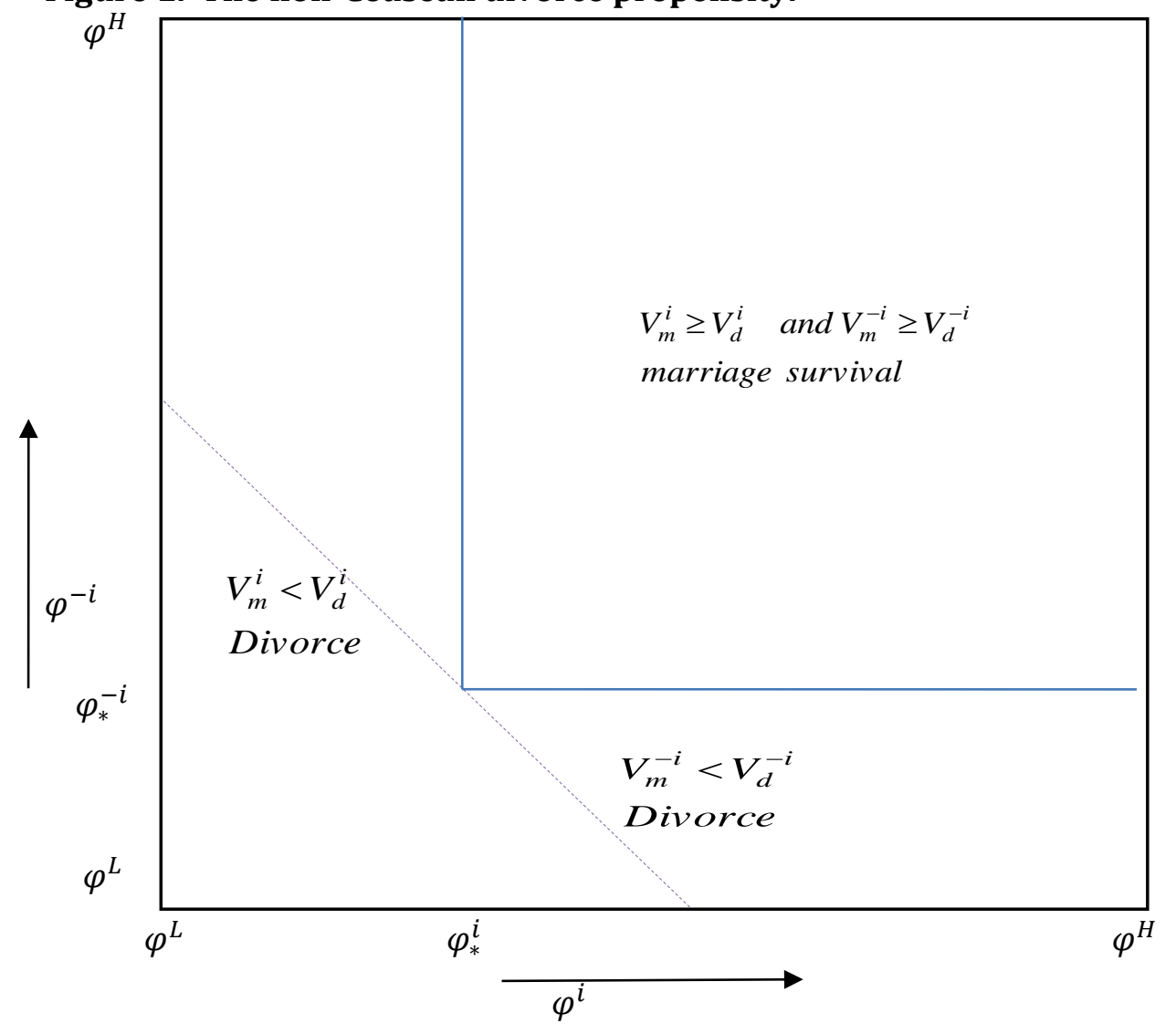




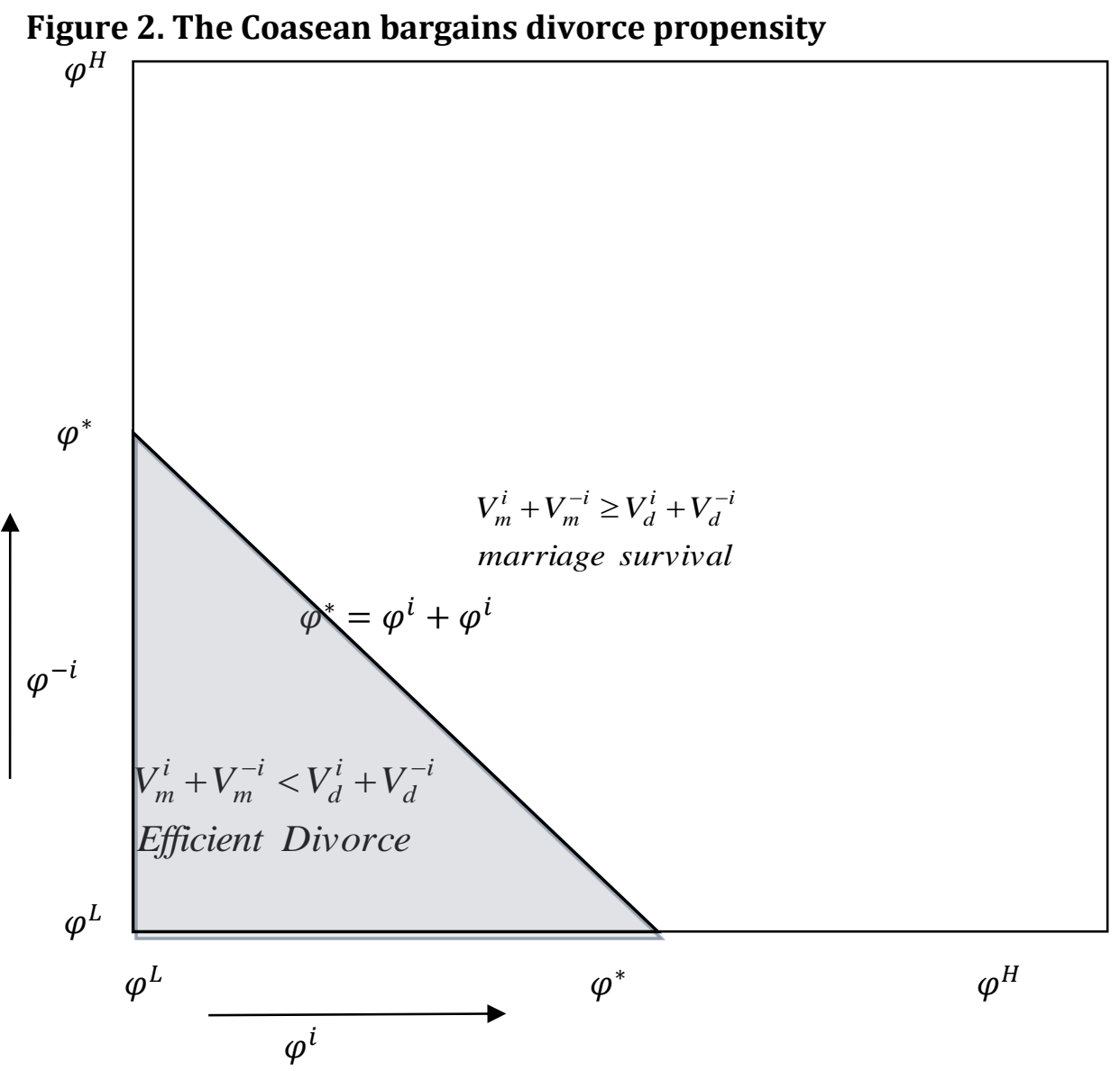

